\title{
Dinâmica da Vazão em uma bacia com plantio de eucalipto em Felixlândia, Minas Gerais.
}

\author{
Otavio Surian Gamba ${ }^{1}$ \\ Herly Carlos Teixeira Dias ${ }^{1}$ \\ Ana Paula Vilela Carvalho ${ }^{1}$ \\ Vanessa Pataro Maffia ${ }^{1}$ \\ José Carlos de Oliveira Junior ${ }^{2}$ \\ Tiago Carvalho de Moaris ${ }^{2}$ \\ Warley Reis Silveira ${ }^{2}$ \\ ${ }^{1}$ Universidade Federal de Viçosa - UFV
}

Av. P.H. Rolfs, Campus UFV-36570-000- Viçosa - MG, Brasil

otavio.gamba@ufv.br; herly@ufv.br; ana.vilela@ufv.br; vpmaffia@yahoo.com.br

${ }^{2}$ Plantar S/A

Departamento de Pesquisa e Meio Ambiente -35794-000- Felixlândia - MG, Brasil warley.silveira@plantar.com.br Jose-oliveira@plantar.com.br Tiago-morais@plantar.com.br

\begin{abstract}
The present study involved the analysis of data of flow, associated with effective rain in a watershed planted with Eucalyptus in Felixlândia, Minas Gerais, during the months of August 2008 to April 2009. Data Flow was collected through an levelloger which allowed readings each hour and the effective rainfall was calculated by adding up the throughfall plus stemflow. To quantify the internal precipitation were placed twelve rain gauges in each plot six between the tree rows and six in the rows spaced 5.25 meters by 2,60 meters in the catchment area of $176.71 \mathrm{~cm}^{2}$. The results obtained so far it appears that the rainfall in the basin causes instantaneous increase in flow. It also appears that there is a big difference in the average flow of the dry season and the average flow of the rainy season showing the temporary source. It is also still not enough data for a more critical analysis of the effects of Eucalyptus that catchment área.
\end{abstract}

Palavras-chave: Eucalyptus, Flow, Effective rain.

\section{Introdução}

Com a expansão dos centros urbanos, a intensificação da industrialização e a ampliação da agricultura irrigada são crescentes a demanda de água tanto para consumo direto como para a utilização em diversas fases da produção, ou para usos não consuntivos (lazer, paisagismo), acirrando a competição. Além disso, a qualidade e a quantidade dos mananciais vêm decrescendo rapidamente pela ação antrópica (EMBRAPA, 2001).

$\mathrm{O}$ uso do solo sem considerar suas características de hidrografia, clima, geologia, cobertura vegetal, podem contribuir para degradação do ambiente. O ecossistema florestal tem um papel fundamental na conservação da água. Assim é de fundamental importância a manutenção dos ecossistemas florestais contidos nas bacias hidrográficas, com a finalidade de preservar esse bioma e através dos processos hidrológicos que ocorrem na bacia, diminuir os efeitos negativos, e aumentar a captação e armazenamento de água.

Percebe-se que ao longo das ultimas décadas uma maior preocupação com a água. Por isso é cada vez mais frequiente, a busca do Manejo integrado de Bacias Hidrográficas, visando sempre adequar a produção com a sustentabilidade. A qualidade e a quantidade de água são afetadas por uma série de fatores externos, tanto naturais quanto antrópicos. O monitoramento da vazão de um curso d'água tem importante papel ao quantificar a disponibilidade de água em uma determinada bacia, além disso, pode-se relacionar a variação da vazão em diferentes épocas do ano a efeitos ambientais e/ou antrópicos. Assim o objetivo deste trabalho foi 
analisar o comportamento da vazão em relação à precipitação efetiva em uma bacia hidrográfica utilizada em quase sua totalidade para produção florestal, localizada em Felixlândia, Minas Gerais.

\section{Materiais e Métodos}

O experimento foi conduzido na bacia hidrográfica do Riacho Fundo, sendo essa uma microbacia que deságua na Represa de Três Marias, Rio São Francisco. A área de drenagem da cabeceira, onde está localizada a estação fluviométrica, está integralmente localizada em terras da PLANTAR, no município de Felixlândia, Minas Gerais. Sua área de 719,92 ha é ocupada em sua maior parte com talhões de eucalipto, $81,7 \%$, possui $8,5 \%$ das terras com estradas florestais e 9,8\% de reserva e APP. O cerrado é o bioma encontrado na Bacia. As características climáticas da região compreendem precipitação media anual de 1118,9 mm com existência de dois períodos distintos predominantes: verão úmido e inverno seco; estação seca de 4 a 5 meses, temperatura media anual de $22{ }^{\circ} \mathrm{C}$, apresentando temperatura media mínima de $16{ }^{\circ} \mathrm{C}$ e media máxima de $30{ }^{\circ} \mathrm{C}$, sendo julho o mês mais frio, e janeiro/fevereiro, os mais quentes do ano. Pela classificação de Köppen, a região enquadra-se no clima Aw, identificado como clima tropical se savana (STRAHLER E STRAHLER, 2002).

Para a mensuração da vazão, encontra-se construído na propriedade, um vertedor triangular, juntamente com um levelloger Solinst modelo 3001 instalado (Figura 1), possibilitando coleta de dados precisos de hora em hora. A leitura do levelloger foi feita através da conexão do dispositivo com um computador, utilizando o software 2.0.2 do levelloger previamente instalado. A coleta foi feita uma vez por mês, entre Agosto de 2008 a Abril de 2009.

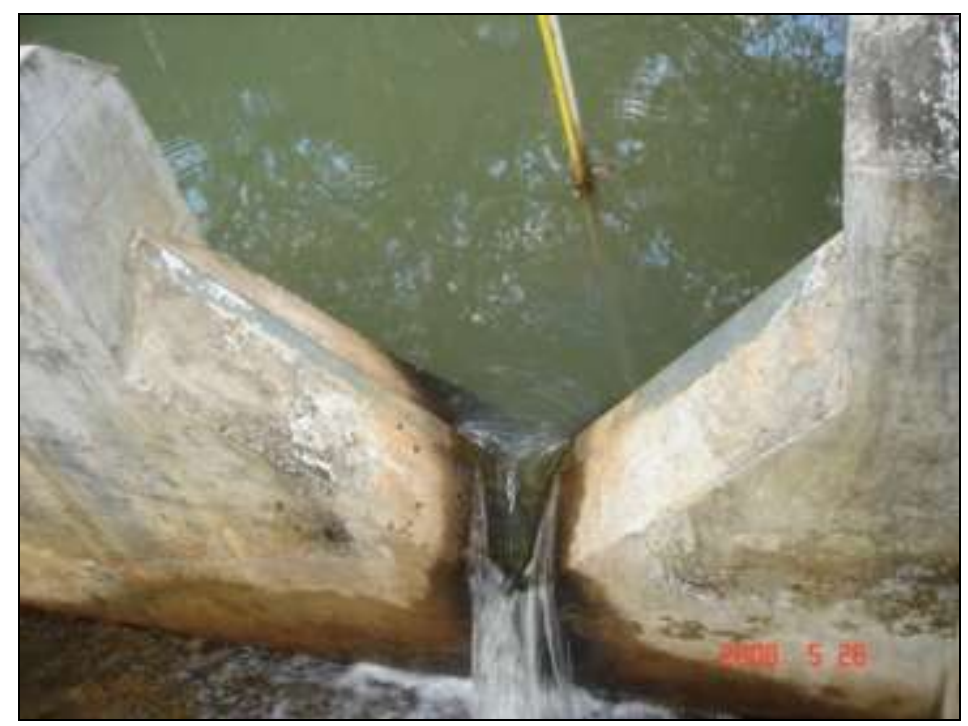

Figura 1: Vertedor triangular localizada na fazenda MG3, onde está instalado o Levelloger. Felixlândia - MG, 2008.

A precipitação efetiva foi calculada somando-se a precipitação interna mais o escoamento pelo tronco. Para quantificar a precipitação interna, foram colocados doze pluviômetros em cada talhão, seis entre as linhas de plantio e seis na linha de plantio espaçado 5,25 metros (m) por 2,60 m e com área de captação de $176,71 \mathrm{~cm}^{2}$ (Figura 2), e para a leitura foi usada uma proveta graduada em $\mathrm{ml}$. 


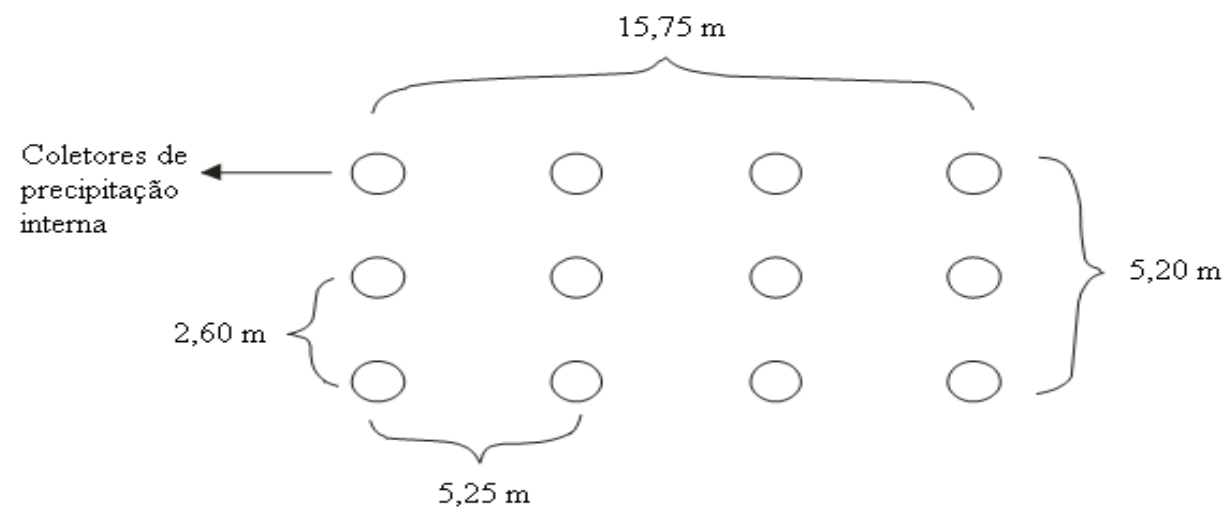

Figura 2: Esquema das parcelas para quantificar a precipitação interna nos talhões, bacia Córrego do Riacho Fundo, Felixlândia - MG, 2008.

Para quantificar o escoamento pelo tronco, foi demarcada uma parcela por talhão e em cada arvore com DAP acima de $15 \mathrm{~cm}$ foram adaptados nove coletores à base de poliuretano nos troncos das árvores, sendo cinco em uma fileira e quatro em outra fileira adjacente, e para a leitura será usada uma proveta graduada em $\mathrm{ml}$.

\section{Resultados e Discussão}

Os dados referentes à vazão diária de hora em hora na Bacia Hidrográfica do Riacho Fundo encontram-se na Tabela 1, sendo esses dados representados graficamente na Figura 3. 
Tabela 1: Medias diárias da vazão em litros por segundo (L/s) na Bacia Hidrográfica do Riacho Fundo, Felixlândia - MG, 2009.

\begin{tabular}{|c|c|c|c|c|c|c|c|c|c|}
\hline & Agosto & Setembro & Outubro & Novembro & Dezembro & Janeiro & Fevereiro & Março & Abril \\
\hline 1 & & 3,73 & 3,10 & 0,00 & 3,68 & 218,16 & 170,60 & 102,26 & 86,63 \\
\hline 2 & & 3,42 & 2,13 & 0,00 & 4,30 & 199,30 & 168,81 & 98,47 & 98,21 \\
\hline 3 & & 3,29 & 2,42 & 0,01 & 3,97 & 203,69 & 152,96 & 94,36 & 107,66 \\
\hline 4 & & 3,29 & 2,44 & 0,00 & 3,48 & 200,20 & 141,31 & 88,86 & 107,58 \\
\hline 5 & & 3,42 & 1,73 & 0,00 & 2,85 & 346,47 & 131,19 & 85,16 & 107,49 \\
\hline 6 & & 3,48 & 1,52 & 0,00 & 2,92 & 279,24 & 128,71 & 85,20 & 107,34 \\
\hline 7 & 6,00 & 3,55 & 1,30 & 0,00 & 2,93 & 254,13 & 121,09 & 84,60 & 111,23 \\
\hline 8 & 6,50 & 3,30 & 0,79 & 0,00 & 2,58 & 227,57 & 115,97 & 91,66 & 108,99 \\
\hline 9 & 6,64 & 3,02 & 0,53 & 0,00 & 2,48 & 202,07 & 110,29 & 81,45 & 109,59 \\
\hline 10 & 6,89 & 2,83 & 0,68 & 0,00 & 1,85 & 177,24 & 102,25 & 80,70 & 109,00 \\
\hline 11 & 6,92 & 2,78 & 1,16 & 0,00 & 1,60 & 157,22 & 101,46 & 77,24 & 109,05 \\
\hline 12 & 6,69 & 2,58 & 0,97 & 0,01 & 1,43 & 142,38 & 113,10 & 74,55 & 108,74 \\
\hline 13 & 6,59 & 2,70 & 0,44 & 0,01 & 2,01 & 128,21 & 185,49 & 72,88 & 107,27 \\
\hline 14 & 7,50 & 2,51 & 0,09 & 0,01 & 5,92 & 117,03 & 352,69 & 71,44 & 108,53 \\
\hline 15 & 8,71 & 2,66 & 0,00 & 0,01 & 11,80 & 106,21 & 363,75 & 81,29 & 108,50 \\
\hline 16 & 8,80 & 2,76 & 0,00 & 0,00 & 20,99 & 103,01 & 353,97 & 78,62 & 107,68 \\
\hline 17 & 9,04 & 3,00 & 0,00 & 0,01 & 21,16 & 96,99 & 323,30 & 77,11 & 108,45 \\
\hline 18 & 8,47 & 3,06 & 0,00 & 0,01 & 17,01 & 86,60 & 265,77 & 71,97 & 108,10 \\
\hline 19 & 8,94 & 2,44 & 0,00 & 0,01 & 12,68 & 81,60 & 214,02 & 66,17 & 108,60 \\
\hline 20 & 8,55 & 2,49 & 0,00 & 0,01 & 11,21 & 78,90 & 192,86 & 65,17 & 102,31 \\
\hline 21 & 8,50 & 3,93 & 0,00 & 0,01 & 9,69 & 90,87 & 175,03 & 63,83 & 94,27 \\
\hline 22 & 8,30 & 4,26 & 0,00 & 0,01 & 12,28 & 88,94 & 160,55 & 63,22 & 91,04 \\
\hline 23 & 8,04 & 1,94 & 0,00 & 0,02 & 12,50 & 133,02 & 153,18 & 66,60 & 88,70 \\
\hline 24 & 8,06 & 1,69 & 0,00 & 0,02 & 11,80 & 108,95 & 146,87 & 84,73 & 87,79 \\
\hline 25 & 8,11 & 2,01 & 0,00 & 0,02 & 81,41 & 101,39 & 130,92 & 79,93 & 84,59 \\
\hline 26 & 7,94 & 4,14 & 0,00 & 3,51 & 109,28 & 146,08 & 121,19 & 84,11 & 82,76 \\
\hline 27 & 7,30 & 5,34 & 0,00 & 7,46 & 123,86 & 211,10 & 113,70 & 74,41 & 81,52 \\
\hline 28 & 7,12 & 3,55 & 0,00 & 4,48 & 108,18 & 222,91 & 106,77 & 75,58 & 78,67 \\
\hline 29 & 6,86 & 3,20 & 0,00 & 4,58 & 193,27 & 207,05 & & 79,99 & 76,17 \\
\hline 30 & & 3,67 & 0,00 & 4,04 & 275,11 & 195,70 & & 92,62 & 75,35 \\
\hline 31 & & & 0,00 & & 242,28 & 180,82 & & 99,02 & \\
\hline Media & 7,67 & 3,14 & 0,64 & 0,81 & 35,81 & 163,74 & 175,64 & 79,81 & 99,06 \\
\hline
\end{tabular}




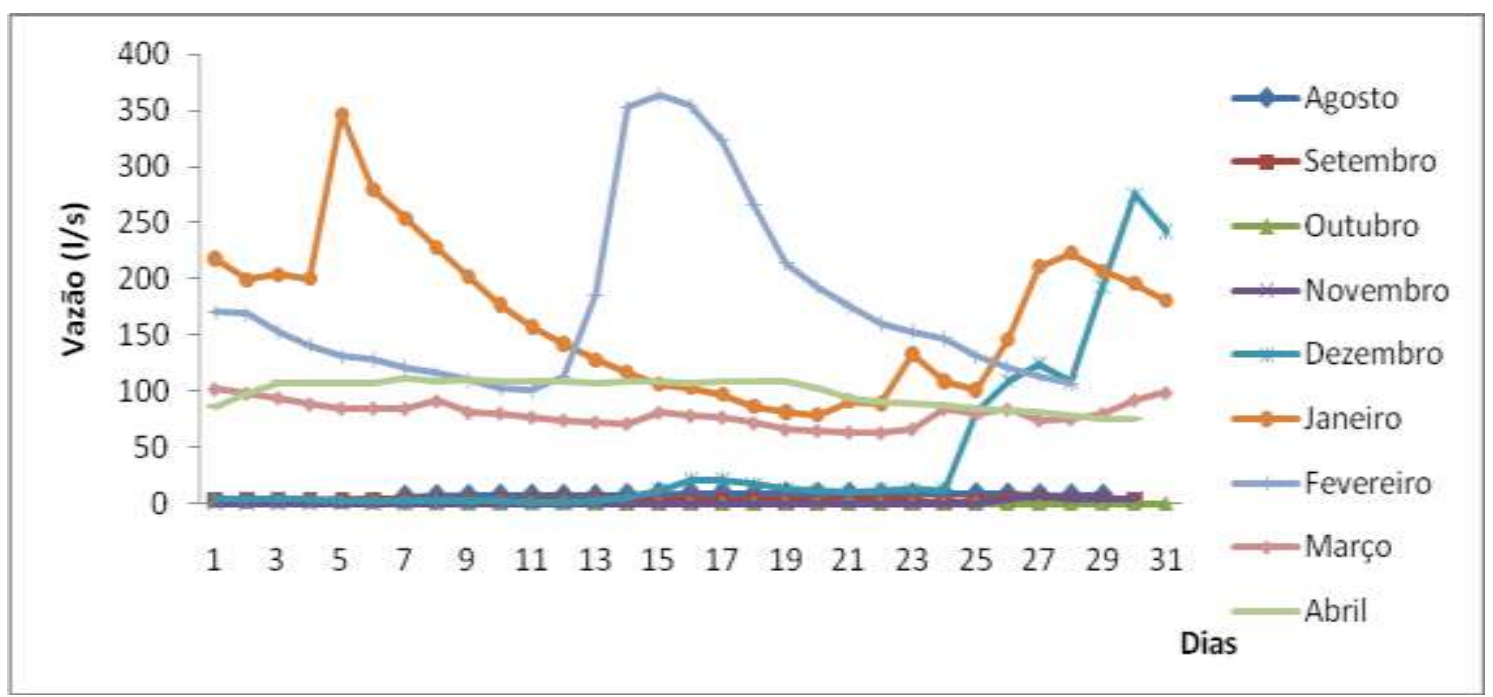

Figura 3: Médias diarias de vazão em litros por segundo na bacia Hidrografica do Riacho Fundo, Felixlandia - MG, 2009.

Pode-se observar que nos meses de janeiro a março a vazão diária é mais elevada em relação aos outros meses, agosto a dezembro. No mês de dezembro, no entanto, observa-se um efetivo aumento na vazão a partir do dia 24. As vazões flutuam diariamente em função dos eventos de chuva. Nos meses de estiagem a vazão são bastante inferiores chegando a zero em alguns dias, provavelmente devido ao caráter temporário das nascentes.

A relação entre a precipitação efetiva e as vazões media mensais no período de estudo encontra-se representada graficamente na Figura 4. Nota-se que a variação da vazão é estritamente ligada com a precipitação, havendo um aumento gradual acentuado na vazão quando entra o período chuvoso começando no final de novembro até a primeira quinzena de abril, onde a precipitação já começa a diminuir, proporcionando a queda da vazão gradualmente. Espera-se que após o mês de abril a vazão decaia ate níveis próximos de zero nos meses seguintes.

A vazão média do período de estiagem, agosto a novembro, é de 3,07 1/s muito inferior a média do período de chuva (dezembro a abril) que foi de 110,81 1/s. O que mais uma vez confirma o caráter temporário da nascente.

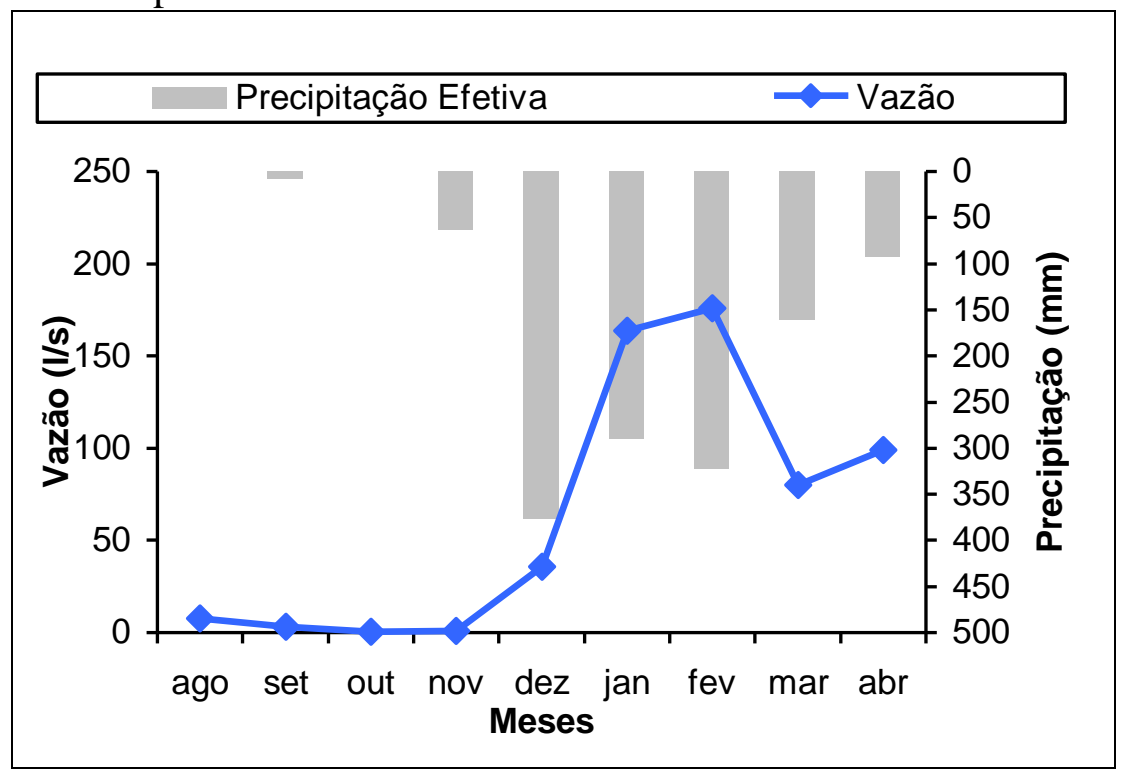

Figura 4: Representações gráficas da vazão em relação à precipitação efetiva entre os meses de agosto de 2008 a abril de 2009, na Bacia Hidrográfica do Riacho Fundo, Felixlândia - MG, 2009. 


\section{Conclusões}

Pelos resultados obtidos até o presente momento conclui-se que a precipitação de chuva na bacia provoca aumento instantâneo na vazão. Conclui-se também que a existe uma grande diferença na vazão média do período de estiagem e a vazão média do período de chuvas demonstrando o caráter temporário da nascente. Os autores agradecem a Plantar reflorestamentos pelo financiamento da pesquisa e a FAPEMIG por facilitar a participação no evento.

\section{Referencias Bibliográficas}

Dias, H.C.T., Martins, S.V. Importância das Florestas para a Quantidade e Qualidade da Água. Ação Ambiental, Viçosa - MG. N.20, p.14-16, 2001.

Empresa Brasileira De Pesquisa Agropecuária - EMBRAPA. Água: Recurso natural finito e estratégico. Sete Lagoas: EMBRAPA Milho e Sorgo, 2001. 20p. (EMBRAPA Milho e Sorgo. Documentos, 16).

Molchanov, A. A. Hidrologia florestal. Lisboa: Fund. Calouste Gulbenkian, 1971. 595p.

Oliveira Junior, J. C. de. Precipitação efetiva em floresta estacional semidecidual na reserva Mata do Paraíso, Viçosa, Minas Gerais. 2006. 72 f. Dissertação (Mestrado em Ciência Florestal) - Universidade Federal de Viçosa, Viçosa.

Santos, G. V.; Dias, H. C. T.; Silva, A. P. S.; Macedo, M. N. C. Análise hidrológica e socioambiental da bacia hidrográfica do córrego Romão dos Reis, Viçosa - MG. Revista Árvore, Viçosa, v. 31, n. 5, 2007.

Thornthwaite, C. W.; Mather, J. R. The water balance. Centerton, New Jersey, Laboratory of climatology, 1955.

Tucci, C.E.M. Hidrologia: ciência e aplicação. 2. ed. Porto Alegre: Ed. Universidade/UFRGS: ABRH, 2001.943p.

Valente, O. F.; Dias, H. C. T. Bacia hidrográfica como unidade de produção de água. Ação ambiental, Viçosa, n. 20, p. $8-9.2001$. 